\title{
Correction to: The role of melatonin in the onset and progression of type 3 diabetes
}

\author{
Juhyun Song ${ }^{1}$, Daniel J. Whitcomb ${ }^{2}$ and Byeong C. Kim ${ }^{3^{*}}$
}

\section{Correction to: Molecular Brain (2017) 10:35 DOI: 10.1186/s13041-017-0315-x}

In the original version of this article [1], published on 1 August 2017, Fig. 3 contains a typo. In this Correction the incorrect and correct version of Fig. 3 are shown.

- Figure 3 was originally published like this:

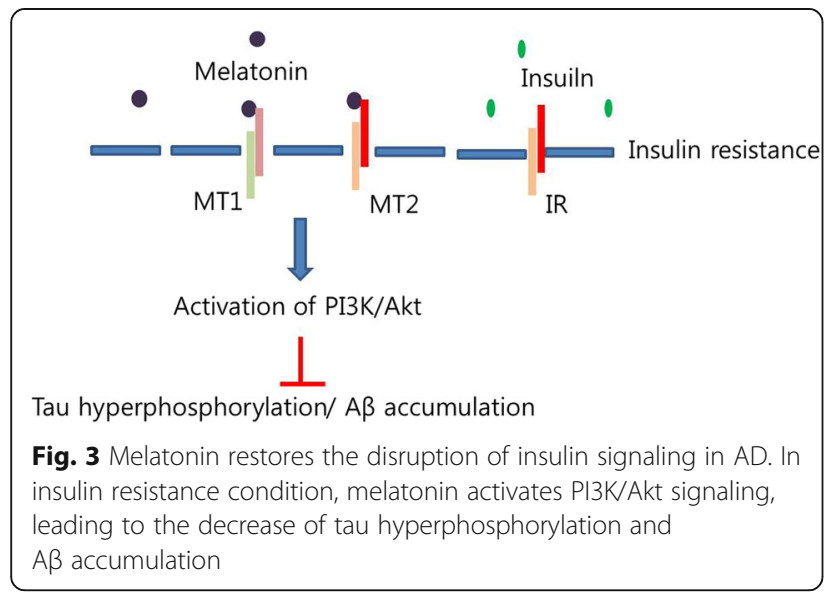

- The correct version of Fig. 3 looks like this:

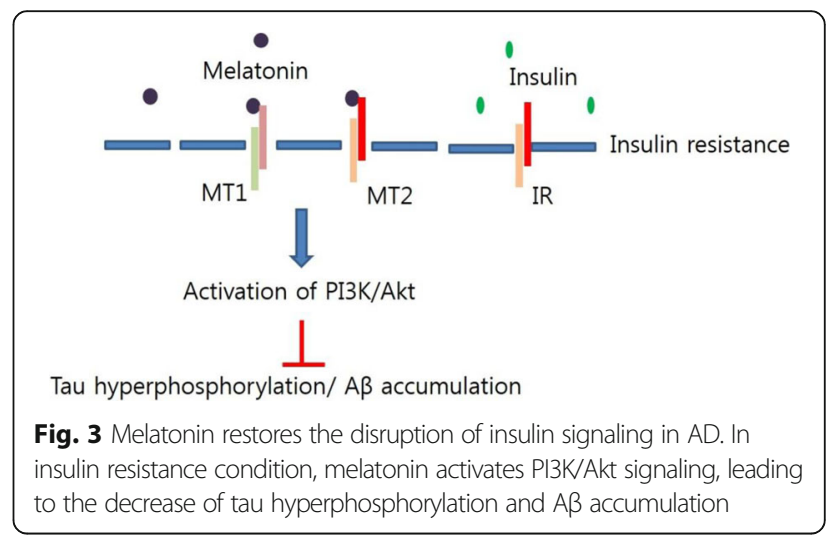

\section{Author details}

${ }^{1}$ Department of Biomedical Sciences, Center for Creative Biomedical Scientists at Chonnam National University, Gwangju 61469, South Korea. ${ }^{2}$ Henry Wellcome Laboratories for Integrative Neuroscience and Endocrinology, School of Clinical Sciences, Faculty of Healthy Sciences, University of Bristol, Whitson street, Bristol BS1 3NY, UK. ${ }^{3}$ Department of Neurology, Chonnam National University Medical School, Gwangju 61469, South Korea.

Received: 27 October 2017 Accepted: 27 October 2017

Published online: 08 December 2017

\section{Reference}

1. Song J, et al. The role of melatonin in the onset and progression of type 3 diabetes. Mol Brain. 2017;10:35. https://doi.org/10.1186/s13041-017-0315-x.

\footnotetext{
* Correspondence: byeong.kim7@gmail.com

${ }^{3}$ Department of Neurology, Chonnam National University Medical School,

Gwangju 61469, South Korea

Full list of author information is available at the end of the article
} 